\title{
Assessing Family Medicine Residents' Preparedness for the Practice of Geriatric Care
}

\author{
Emily Ingram, MD | Owen Dunkley, BSc | Karen Willoughby, MD, PhD | Mark Yaffe, MD, MCISc | \\ Charo Rodríguez, MD, PhD
}

PRIMER. 2019;3:15.

Published: 5/31/2019 | DOI: 10.22454/PRiMER.2019.488305

\section{Abstract}

Introduction: Family physicians provide care to a growing and often complex group of older adults. Family medicine residencies are expected to prepare trainees to manage the medical and social needs of these seniors, but whether they feel prepared to do so is unknown. This study aimed to assess family medicine residents' sense of preparedness to address geriatric-related issues, and to identify factors that might affect this self-evaluation.

Methods: As an exploratory cross-sectional study, a 28-item questionnaire was circulated among 180 McGill University family medicine residents for voluntary completion. The survey assessed residents' demographics, attitudes toward, and perceptions of their training in geriatrics.

Results: One hundred residents (55.5\% response rate) completed the questionnaire. Residents perceived their level of preparedness increasing as they progressed in their training; however, they felt least comfortable managing behavioral problems and engaging community resources. Positive perceptions about their training for geriatric care was proportionate to the number of positive role models they had during training. Sense of preparedness was most strongly and significantly associated with the duration of exposure residents had to long-term care.

Conclusion: The aging population requires physicians who are interested in care of the elderly and who are adequately prepared through comprehensive training to care for the complex medical and social issues that affect this large segment of society. This study, through its survey of family medicine residents, provides insights about potential curriculum changes and recommendations for updating the approach to care of the elderly.

\section{Introduction}

In 2016 , approximately $16.9 \%$ of the Canadian population was aged 65 years or older, a rate expected to reach $23.7 \%$ of the Canadian population by $2036 .{ }^{1}$ Care of the elderly is a function of family doctors; however, with the proportion of the elderly growing, and living with increasingly complex medical and social problems, there is an onus on the discipline of family medicine to ensure that its trainees are adequately prepared. In Canada, there is not only a shortage of geriatricians, but evidence of inadequate elderly care by primary care physicians. ${ }^{2-4}$

Elderly care training in McGill University's 2-year family medicine residency takes place during a combination of one geriatrics rotation, during numerous weekly longitudinal continuity of care family medicine clinics, and possibly during electives. It is unknown whether these trainees ultimately feel prepared to provide comprehensive care in 
various settings to seniors. While competency to practice has been explored among residents in other specialty training programs, ${ }^{5,6}$ to our knowledge it is yet to be studied in Canadian postgraduate family medicine. In this study, we aimed to answer two central questions: (1) To what extent do family medicine residents feel prepared to address care of the elderly? (2) What are the factors that they think mediate their perceptions of preparedness? Underlying these questions was a desire to develop a curriculum and learning experiences for elder care that were evidencebased.

\section{Methods}

\section{Questionnaire Structure}

This cross-sectional study used a 28-question survey developed by our team specifically for this project. It was separated into demographic, quantitative (Likert, multiple choice and binary), and open-ended questions. The full survey is available on the STFM Resource Library. ${ }^{7}$ The quantitative portion assessed preparedness as a multidimensional construct, composed of the following variables: attitudes of residents toward older persons and their care, self-perceived preparedness to treat specific types of patients and manage specific conditions, selfassessment of clinical skills, amount of training and instruction in geriatric care, role models, and future plans on caring for the elderly. Resident attitudes toward the elderly were assessed using 5-point Likert-type questions with positive and negative items to test for acquiescence response bias. The items chosen to assess resident attitudes were taken from a 14-item, 4-dimensional geriatrics attitudes scale developed by Reuben et al that demonstrated high reliability (Cronbach $\mathrm{a}=0.76$ ) and validity. ${ }^{8}$ Self-perceived preparedness and self-assessment of skills were evaluated based on respondents' current perceptions, as well as their retrospective perceptions of their own preresidency qualities. The Institutional Review Board of McGill University's Faculty of Medicine granted the study ethics approval.

\section{Questionnaire Implementation}

Between July and August of 2016, paper questionnaires were delivered to first- and second-year family medicine residents at the three main McGill training sites. Residents at distant training sites received identical questionnaires by email, using surveygizmo.com. Participation was voluntary and was incentivized by a $\$ 5$ gift card offered to those who completed the survey.

\section{Data Analysis}

Quantitative analysis of questionnaire data was performed using SAS/STAT, permitting calculation of mean and standard deviation values for individual items, composite scores for outcome variables, and linear regression coefficients $(\beta)$. SPSS 21 was used to calculate Cronbach a $(\mathrm{Ca})$, a measure of internal consistency for each outcome dimension. Some missing data occurred because some participants missed a single item, while eight participants (8\%) did not fully complete the questionnaire. Missing values were imputed using the expectationmaximization (EM) method. EM retains cases that are missing, thus avoiding the biased estimates that can occur with pairwise or listwise deletion. ${ }^{9}$

\section{Results}

One hundred residents (55.5\% response rate) completed the questionnaire. Demographic data are presented in Table 1 , showing respondents represented a good sampling of the entire family medicine residency population at McGill University. Overall, residents felt moderately prepared (mean=3.68/5, SD=0.55; $1=$ not at all prepared, $5=$ very prepared) to care for the elderly. As residents progressed in their training, their perceived level of preparedness to deal with a list of common geriatric problems increased, as did their skill in common geriatric care tasks (Figure 1, Table 2). This change in preparedness significantly correlates with the amount of training residents had for each problem $(\beta=0.41, P=.0001)$.

In a univariate analysis, the number of clinical role models was significantly associated with residents' overall rating of their medical training $(\beta=0.58, P<.0001)$. The combined number of role models in all geriatric training settings 
also showed a positive influence $(\beta=0.21, P<.0001$; Figure 2$)$. Similarly, in a multivariate model using Bayesian information criterion (BIC) selection of all independent variables, the total amount of geriatric care role models seen in all residency rotations had a lesser, yet significant positive effect on overall training rating, as did the number of months of residency, total number of geriatric environments in their training, and amount of training in elderly care (Figure 3). Furthermore, the greatest predictor for planning to include elderly care in future practice was their number of home care role models $(\beta=0.32, P=.0225)$.

Using BIC selection, residents who felt the most prepared for elderly care had finished more months of residency $(\beta=0.20, P<.0001)$, were younger $(\beta=0.27, P=.0044)$, had exposure to long-term care $(\beta=0.18, P=.0001)$ and were male (odds ratio $=0.41, P<.0001$ ). The number of role models, amount of clinic time devoted to elderly patients, and home care visits did not significantly affect how residents rated their preparedness.

\section{Conclusions}

The results of this study suggest that there is room for improving family medicine postgraduate education on care of the elderly. It also suggests ways to enhance residents' sense of preparedness to care for elderly patients, and to improve the quality of their training. While some elements are not modifiable by the faculty (eg, preceptor age and gender), others can be changed at the curriculum level. Increasing both exposure to long-term care and home-care patients will benefit residents in their sense of preparedness. Our results suggest that having more role model interactions in geriatrics at family medicine training sites will have the greatest impact on how residents view their care-of-the-elderly training. The importance of strong role models at residency sites suggests a focus for both faculty development and continuing professional education, common to medical education in Canada and elsewhere. ${ }^{10,11}$

A study limitation might be the low response rate (55.5\%). However, a mixed-studies literature review of family physicians' participation in research work by Sahin et al showed that family physician recruitment rate into research projects ranges from $2 \%$ to $81 \% .{ }^{12}$ In the context of such findings, the response rate in our study should be viewed as at least average. Nonetheless, a self-selection bias may have influenced our findings.

Our survey was given at one point in time in one faculty program, which narrows the generalizability of the results. Standardized testing given at different time points during postgraduate training would provide a better picture of the evolution of preparedness for elderly care during residency programs.

At this time, there are no standardized evaluations within Canada used in care of the elderly training. These preliminary results could be used by the College of Family Physicians to set their program requirements. The questionnaire could be used at other family medicine units to determine the current state of care-of-the-elderly training in Canada.

\section{Tables and Figures}


Table 1: Demographic Variables

\begin{tabular}{|c|c|c|c|c|}
\hline Variable & Result & $n($ of 100$)$ & Expected* & $\begin{array}{c}\text { Response } \\
\text { Rate }^{* *}\end{array}$ \\
\hline \multirow[t]{2}{*}{ Age } & $\begin{array}{c}\text { Mean=29.00, } S D=4.56, \\
\text { range }=23-48\end{array}$ & 97 & & \\
\hline & Undeclared & 3 & & \\
\hline \multirow{5}{*}{ Months of residency completed } & $0-6$ & 9 & \multirow{2}{*}{95} & \multirow{2}{*}{$56.8 \%$} \\
\hline & $7-12$ & 45 & & \\
\hline & $13-18$ & 4 & \multirow{2}{*}{85} & \multirow{2}{*}{$48.2 \%$} \\
\hline & $19-24$ & 37 & & \\
\hline & $>24$ & 5 & & \\
\hline \multirow{3}{*}{ Gender } & Male & 34 & 66 & $51.5 \%$ \\
\hline & Female & 65 & 114 & $57.0 \%$ \\
\hline & Undeclared & 1 & & \\
\hline \multirow{3}{*}{ Geriatrics rotation } & Completed & 63 & & \\
\hline & Not completed & 34 & & \\
\hline & Undeclared & 3 & & \\
\hline \multirow{7}{*}{ Training site } & St Mary's & 42 & 54 & $77.8 \%$ \\
\hline & Herzl & 23 & 46 & $50.0 \%$ \\
\hline & cSss & 16 & 36 & $44.4 \%$ \\
\hline & Gatineau & 10 & 22 & $45.5 \%$ \\
\hline & Chateauguay & 4 & 15 & $26.6 \%$ \\
\hline & Val D'Or & 3 & 7 & $42.9 \%$ \\
\hline & Undeclared & 2 & & \\
\hline
\end{tabular}

* Expected values are based on the demographics of all 180 McGill Family Medicine residents active during the surveyed academic year. These data were provided by the McGill Department of Family Medicine.

${ }^{* *}$ Response rates were calculated as the percentage of each demographic that completed the survey. 
Table 2A: Self-assessments of Preparedness in Managing Common Geriatric Problems, Listed by Ascending Current Rating on a Five-Point Likert Scale (1=Not at All Prepared, 5=Very Prepared)

\begin{tabular}{|c|c|c|}
\hline Variable & $\begin{array}{c}\text { Prior to Residency } \\
\text { Mean=2.59, } \\
\text { SD=0.40 (Co.086) }\end{array}$ & $\begin{array}{c}\text { Current Mean=3.58, } \\
\text { SD=0.29 (Co=0.901) }\end{array}$ \\
\hline Behavioral problems & \multicolumn{2}{|c|}{ Mean (SD) Range: 1-5 } \\
\hline Urinary incontinence & $2.15(0.73)$ & $3.25(0.86)$ \\
\hline Functional decline & $2.64(0.83)$ & $3.45(0.69)$ \\
\hline Dizziness & $2.44(0.79)$ & $3.54(0.79)$ \\
\hline Polypharmacy & $2.70(0.90)$ & $3.57(0.80)$ \\
\hline Dementia & $2.53(0.87)$ & $3.67(0.82)$ \\
\hline Depression & $2.89(0.85)$ & $3.69(0.73)$ \\
\hline Falls & $3.04(0.85)$ & $3.80(0.71)$ \\
\hline Delirium & $2.89(0.78)$ & $3.86(0.72)$ \\
\hline Osteoporosis & $3.12(0.79)$ & $3.96(0.74)$ \\
\hline
\end{tabular}

Table 2B: Self-assessments of Skill Level With Common Geriatric Care Tasks, Listed by Ascending Current Rating on a Five-Point Likert Scale (1=Not at All Skillful, 5=Very Skillful)

\begin{tabular}{|c|c|c|}
\hline Variable & $\begin{array}{l}\text { Prior to Residency } \\
\text { Mean }=2.722, \\
S D=0.30\left(C_{0}=0.869\right)\end{array}$ & $\begin{array}{l}\text { Current Mean=3.68, } \\
\mathrm{SD}=0.23\left(\mathrm{C}_{0}=0.930\right)\end{array}$ \\
\hline & \multicolumn{2}{|c|}{ Mean (SD) Range: 1-5 } \\
\hline Attending to elder abuse & $2.06(0.93)$ & $3.05(1.02)$ \\
\hline Referring patients to appropriate community resources to optimize their care & $2.06(0.85)$ & $3.22(0.88)$ \\
\hline Recognizing elder abuse & $2.35(0.85)$ & $3.36(0.96)$ \\
\hline Identifying red flags in capacity to drive & $2.43(0.89)$ & $3.45(0.91)$ \\
\hline Discussing advance directives & $2.25(0.89)$ & $3.45(1.04)$ \\
\hline Attending to caregiver stress & $2.51(0.83)$ & $3.46(0.87)$ \\
\hline Optimizing medication & $2.30(0.82)$ & $3.54(0.79)$ \\
\hline Discussing and assisting with changes in living environment & $2.59(0.79)$ & $3.57(0.78)$ \\
\hline Discussing concerns over patients with dementia with families and caregivers & $2.66(0.79)$ & $3.63(0.81)$ \\
\hline Recognizing caregiver stress & $2.98(0.83)$ & $3.71(0.79)$ \\
\hline $\begin{array}{l}\text { Collaborating with other health care professionals in the community } \\
\text { (pharmacist, nurse, social worker, occupational therapist, etc) }\end{array}$ & $2.69(0.99)$ & $3.81(0.84)$ \\
\hline Assessing mental capacity for ADLs and IADLs & $3.08(0.84)$ & $3.83(0.83)$ \\
\hline Assessing functional status & $2.88(0.77)$ & $3.86(0.71)$ \\
\hline Doing a physical exam & $3.46(0.69)$ & $4.20(0.64)$ \\
\hline
\end{tabular}

Abbreviations: ADLs, activities of daily living; IADLs, instrumental activities of daily living. 
Figure 1: Linear Univariate Model Showing the Influence of the Number of Months in Residency Has on Residents' Assessment of Their Current Preparedness to Deal With Common Geriatric Problems $\left(C_{\chi}=0.901 ; \beta=0.20, P<0.0001\right)$

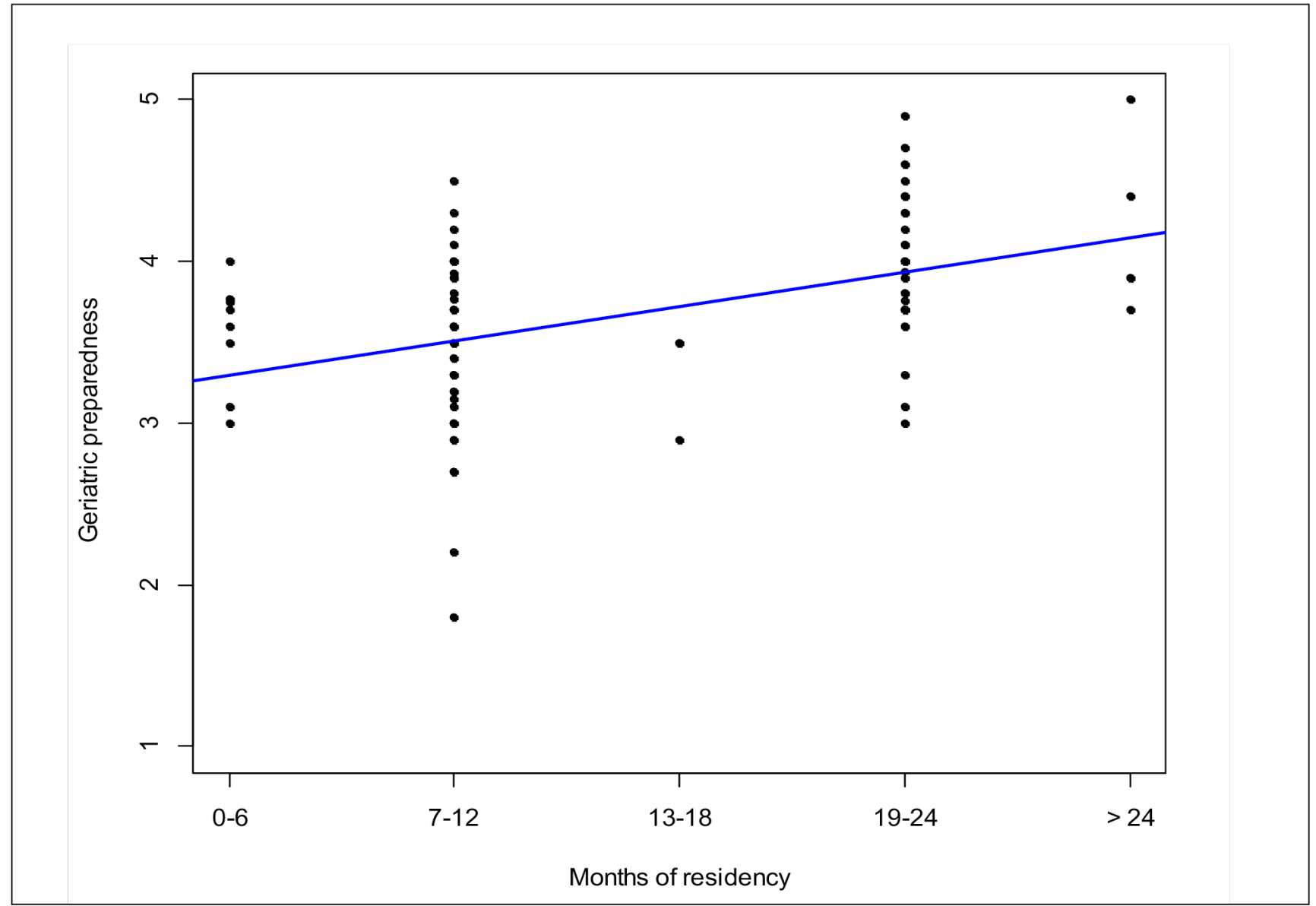


Figure 2: Linear Univariate Model Showing the Influence of the Total Number of Geriatric Care Role Models on Residents' Overall Training Rating $(\beta=0.21, P<0.0001)$. *Overlapping Points Appear as One.

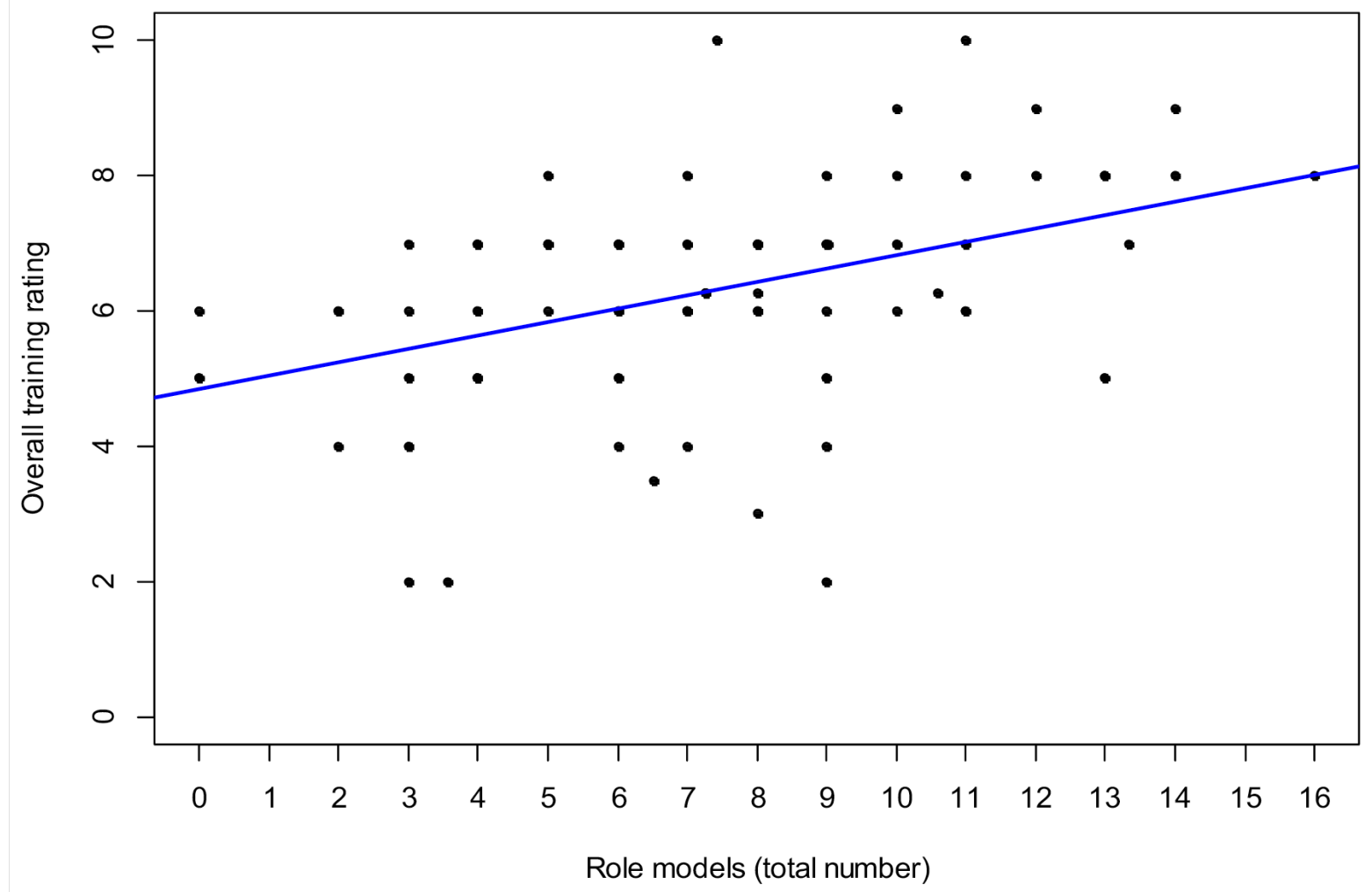

Figure 3: Factors Positively Influencing Residents' Overall Assessment of Their Geriatric Training (Assessed Through BIC Selection)

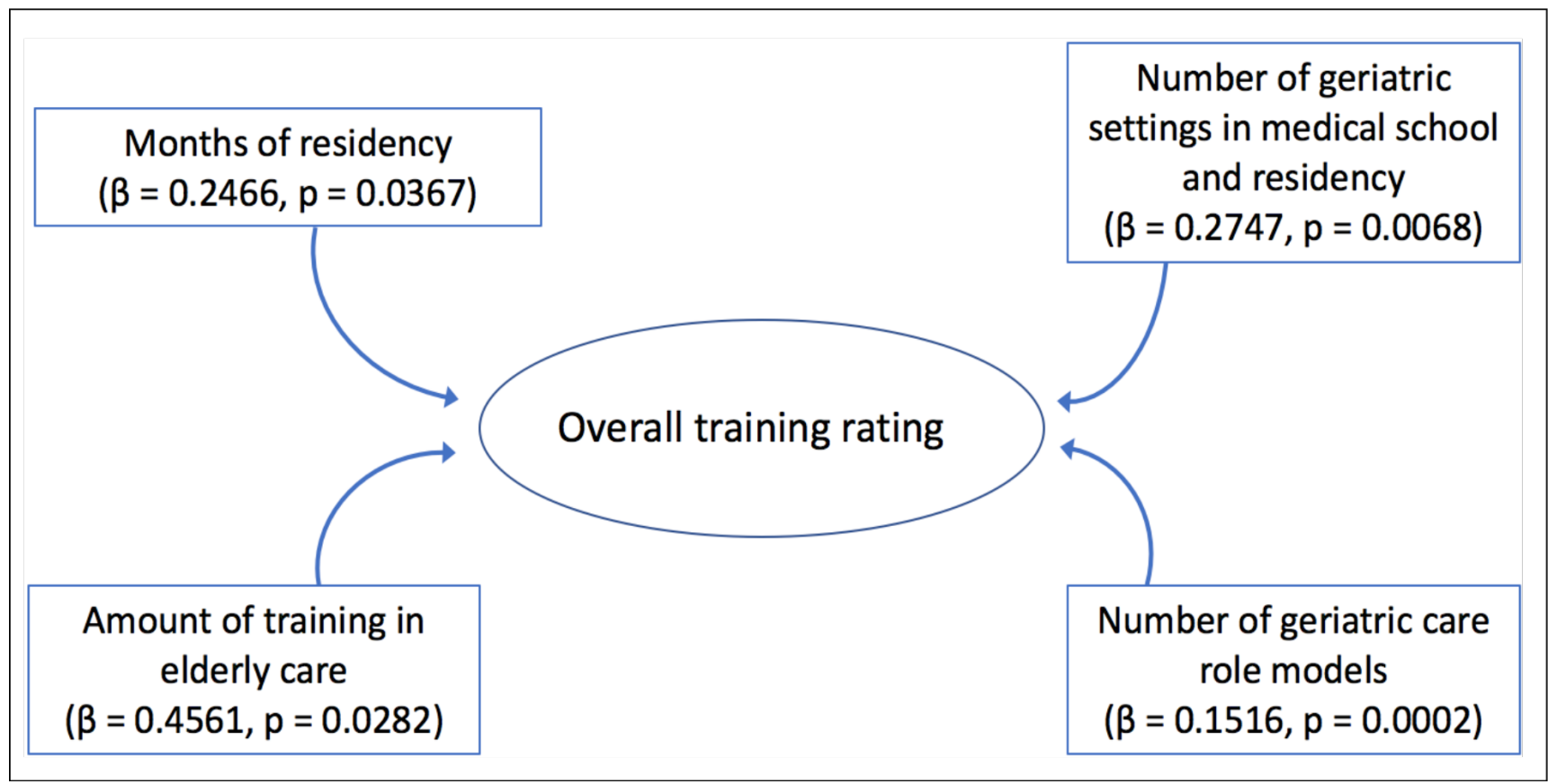

Acknowledgments 
Funding for this project was provided by the Janus Research Grant of the College of Family Physicians of Canada.

The authors thank Alina Dyachenko at Saint Mary's Research Centre for helping analyze and interpret survey data.

Prior Presentation: Ingram E, Dunkley O, Rodriguez C, Yaffe M, Willoughby K. Family medicine residents' eldercare learning experience and its impact on preparedness for caring for the elderly. North American Primary Care Research Group Annual Meeting. Montreal, QC. November 2017.

IRB Review Number: Institutional Review Board of McGill University's Faculty of Medicine, A04-E40-14B

\section{Corresponding Author}

Emily Ingram, MD

St-Mary's Hospital Family Medicine Centre, 3777 Jean-Brillant, Montreal, QC H3T 1M5, Canada. 1-514-692-0109.

Fax: 1-514-734-2605.

emily.ingram@mcgill.ca

\section{Author Affiliations}

Emily Ingram, MD - Department of Family Medicine, McGill University, Quebec, Canada I Department of Family Medicine, St. Mary's Hospital Center, Montreal, Quebec, Canada I Integrated University Centre for Health and Social Services of West Island of Montreal

Owen Dunkley, BSc - Saint Mary's Research Center, McGill University, Quebec, Canada

Karen Willoughby, MD, PhD - Department of Family Medicine, Faculty of Medicine, Memorial University of Newfoundland, St John's, Newfoundland, Canada

Mark Yaffe, MD, MCISc - Department of Family Medicine, McGill University, Montreal, Quebec, Canada I Department of Family Medicine, St. Mary's Hospital Center, Montreal, Quebec, Canada I Integrated University Centre for Health and Social Services of West Island of Montreal

Charo Rodríguez, MD, PhD - McGill University Department of Family Medicine, Montreal, Quebec, Canada

\section{References}

1. Statistics Canada. Annual Demographic Estimates: Canada, Provinces and Territories. Vol 91-215-X. Ottawa, ON. 2012.

2. Lazarou J, Pomeranz BH, Corey PN. Incidence of adverse drug reactions in hospitalized patients: a metaanalysis of prospective studies. JAMA. 1998;279(15):1200-1205. https://doi.org/10.1001/jama.279.15.1200

3. Steinweg KK. Embracing the ecology of geriatrics to improve family medicine education. Fam Med. 2008;40(10):715-720.

4. Reuben DB, Roth $C$, Kamberg $C$, Wenger NS. Restructuring primary care practices to manage geriatric syndromes: the ACOVE-2 intervention. J Am Geriatr Soc. 2003;51(12):1787-1793. https://doi.org/10.1046 /j.1532-5415.2003.51565.x

5. Shipway DJ, Partridge JS, Foxton CR, et al. Do surgical trainees believe they are adequately trained to manage the ageing population? A UK survey of knowledge and beliefs in surgical trainees. J Surg Educ. 2015;72(4):641-647. https://doi.org/10.1016/j.jsurg.2015.01.019

6. Snider T, Melady D, Costa AP. A national survey of Canadian emergency medicine residents' comfort with geriatric emergency medicine. CJEM. 2017;19(1):9-17. https://doi.org/10.1017/cem.2016.27

7. Ingram E, Yaffe M, Rodriguez C, et al. McGill Family Medicine Residents' Preparedness for Geriatric Care Survey. 2015. STFM Resource Library. https://resourcelibrary.stfm.org/viewdocument/mcgill-family-medicineresidents-p?CommunityKey=2751b51d-483f-45e2-81de-4faced0a290a. Accessed May 9, 2019.

8. Reuben DB, Lee M, Davis JW Jr, et al. Development and validation of a geriatrics attitudes scale for primary care residents. J Am Geriatr Soc. 1998;46(11):1425-1430. https://doi.org/10.1111

/j.1532-5415.1998.tb06012.x

9. Schafer JL, Graham JW. Missing data: our view of the state of the art. Psychol Methods. 2002;7(2):147-177. https://doi.org/10.1037/1082-989X.7.2.147 
10. Maudsley RF. Role models and the learning environment: essential elements in effective medical education. Acad Med. 2001;76(5):432-434. https://doi.org/10.1097/00001888-200105000-00011

11. Jochemsen-van der Leeuw HG, van Dijk N, van Etten-Jamaludin FS, Wieringa-de Waard M. The attributes of the clinical trainer as a role model: a systematic review. Acad Med. 2013;88(1):26-34. https://doi.org/10.1097 /ACM.0b013e318276d070

12. Sahin D, Yaffe MJ, Sussman T, McCusker J. A mixed studies literature review of family physicians' participation in research. Fam Med. 2014;46(7):503-514.

Copyright $(2019$ by the Society of Teachers of Family Medicine 